\title{
DETECTION OF A PUTATIVE NOVEL ADENOVIRUS BY PCR AMPLIFICATION, SEQUENCING AND PHYLOGENETIC CHARACTERISATION OF TWO GENE FRAGMENTS FROM FORMALIN-FIXED PARAFFIN-EMBEDDED TISSUES OF A CAT DIAGNOSED WITH DISSEMINATED ADENOVIRUS DISEASE
}

\author{
Béla LAKATOs ${ }^{1,2}$, Ákos HoRNYÁK ${ }^{3}$, Zoltán DEMETER ${ }^{1 \S}$, Petra ForGÁCH ${ }^{1}$, \\ Frances KENNEDY ${ }^{4}$ and Miklós RUSVAI ${ }^{1 *}$ \\ ${ }^{1}$ University of Veterinary Medicine, István u. 2, H-1078 Budapest, Hungary; \\ ${ }^{2}$ Lakat-Vet Bt., Budapest, Hungary (present address); ${ }^{3}$ NFCSO VDD Department of \\ Virology, Budapest, Hungary; ${ }^{4}$ Department of Radiology, Michigan State University, \\ East Lansing, MI, USA
}

(Received 28 June 2017; accepted 6 November 2017)

\begin{abstract}
Adenoviral nucleic acid was detected by polymerase chain reaction (PCR) in formalin-fixed paraffin-embedded tissue samples of a cat that had suffered from disseminated adenovirus infection. The identity of the amplified products from the hexon and DNA-dependent DNA polymerase genes was confirmed by DNA sequencing. The sequences were clearly distinguishable from corresponding hexon and polymerase sequences of other mastadenoviruses, including human adenoviruses. These results suggest the possible existence of a distinct feline adenovirus.
\end{abstract}

Key words: Adenovirus, cat, PCR, FFPE, hexon, DNA polymerase

Adenoviruses (AdVs) are icosahedral non-enveloped double-stranded DNA viruses that are widespread in vertebrates. The gene of the main capsid protein, called hexon, contains highly conserved regions that make them ideal for genus-specific hybridisation probe (Scott and Hammond, 1992), and to design primers for the detection of AdVs by polymerase chain reaction (PCR) in clinical samples (Allard et al., 1990; Horváth et al., 1996). Regarding adenovirus disease in humans, severe lymphopenia and the detection of adenovirus DNA in blood is usually predictive of disseminated disease (Chakrabarti et al., 2004; Echavarría et al., 2001). PCR is suitable for grouping human adenoviruses (HAdVs) as well (Pring-Åkerblom and Adrian, 1994). Probably, the actual number of known ade-

\footnotetext{
${ }^{\S}$ Present address: Department of Pathobiology, College of Veterinary Medicine, University of Illinois, Urbana, IL 61802, USA;

*Corresponding author; E-mail: Rusvai.Miklos@univet.hu; Phone: 0036 (20) 915-67-88
} 
novirus types of a given host species reflects the effort made to detect the virus or obtain an isolate rather than the real frequency of occurrence (Wadell, 1984).

The strongly conserved amino acid (aa) sequence motifs forming the enzymatic active centre of the DNA-dependent DNA polymerase of AdVs have provided a possibility for designing highly degenerate consensus primers for a sensitive nested PCR that is suitable for the general detection of virtually any member of the family Adenoviridae (Wellehan et al., 2004; Kaján et al., 2011; Vidovszky et al., 2015).

The genetic material of microorganisms, extracted from formalin-fixed paraffin-embedded (FFPE) tissue, has been used successfully in high-throughput assays, particularly when short fragments of the nucleic acids were targeted (Little et al., 2006; Jacobs et al., 2007; Oosting et al., 2007; Killian et al., 2009). In spite of different limitations compared to fresh or frozen materials, FFPE samples can be an archival source of biological material for retrospective epidemiological investigations (Huang et al., 2010).

Diagnosis of adenovirus infection has been obtained from FFPE tissue samples by direct and indirect immunofluorescence (Chandler and Gorelkin, 1983), in situ DNA hybridisation (Smyth et al., 1996, 1999) and by PCR (Chouinard et al., 1998; Garcia-Morante et al., 2016).

Disseminated adenovirus infection in a cat, also infected with feline leukaemia virus (FeLV), has been described in a case report (Kennedy and Mullaney, 1993). An 8-year-old, spayed female, domestic short-haired cat kept with horses, dogs and a goat, and infected with FeLV was presented moribund. At necropsy, samples from multiple organs were taken, fixed in 10\% neutral buffered formalin and embedded in paraffin. In routine haematoxylin and eosin stained sections, inclusion bodies typical of $\mathrm{AdV}$ infection were detected in endothelial cells. Formalin-fixed samples of the small intestinal mesentery were examined with an electron microscope; the detached endothelial cells contained icosahedral structures forming loose crystalline arrays typical of adenovirus particles (Kennedy and Mullaney, 1993). A report of inclusion body hepatitis in a black panther (Panthera pardus pardus) has raised the suspicion of adenovirus infection, but there was no virologic or electron microscopic confirmation of the causative agent in that case (Gupta, 1978). Adenovirus antibody detection by an indirect ELISA employing a genus-specific hexon antigen was performed in multiple cat populations (Lakatos et al., 1996, 1999b, 2000). The seropositivity varied between 10 and $26 \%$ in field samples. However, the antibody prevalence was 50 $80 \%$ in animals infected by FeLV and feline immunodeficiency virus (FIV), i.e. in cats suffering from virus infections potentially causing immunodeficiency (Lakatos et al., 1996, 1999b).

A previously unknown, partial hexon gene fragment has been obtained by PCR from rectal and pharyngeal swab samples of a FIV-infected cat (Lakatos et al., 1999a). The sequence was identified as originating from HAdV-1 later, when 
the full genomic sequence of HAdV-1 was published (Lauer et al., 2004). Subsequently, the presence of HAdV-1 was confirmed in cats in Japan (Phan et al., 2006) and Brazil as well (Luiz et al., 2010), but no other reports on sequencelevel identification of AdVs in felid hosts have been published to date.

In the present communication we describe the retrospective molecular biological detection and partial characterisation of a putative novel AdV in the archived FFPE samples originating from the above-mentioned cat (Kennedy and Mullaney, 1993).

\section{Materials and methods}

Sample and purification of the nucleic acid

Ten-micrometre sections from the FFPE sample (containing multiple organs, including liver and spleen) were pooled. The FFPE DNA Extraction Kit (Qiagen, Germany) was used for the purification of nucleic acid according to the manufacturer's instructions.

\section{PCR primers}

We used a primer pair that originally had been described for the detection of HAdVs (Allard et al., 1990), then slightly modified by introducing certain degeneracy (Kiss et al., 1996). These primers amplify a PCR product of 300 base pairs (bp) from the hexon gene of almost every mammalian adenovirus. The target region codes for the most conserved basal part of the beta-barrel-forming P1 domain of the hexon protein (Kiss et al., 1996). The primers were synthesised by the Custom Primer Service of Life Sciences B.V. (Breda, The Netherlands). For the PCR amplification of the DNA polymerase gene fragment, a slightly modified version of the PCR published by Wellehan et al. (2004) was applied, as follows: instead of nested PCR, just a simple conventional PCR was performed using the inner forward and the outer reverse primers in pair. The expected size of the amplicon was around $500 \mathrm{bp}$. These primers were synthesised by the Custom Primer Service of the Biological Research Centre of the Hungarian Academy of Sciences (Szeged, Hungary).

\section{PCR assays}

PCR amplification was carried out in a $100-\mu \mathrm{l}$ volume containing $10 \mu \mathrm{l}$ of $10 \mathrm{x}$ reaction buffer containing $1.5 \mathrm{mM} \mathrm{MgCl}_{2}, 50 \mathrm{pmol}$ of each primer, $2 \mathrm{U}$ of thermostable Taq DNA polymerase (Fermentas, Vilnius, Lithuania), $300 \mu \mathrm{M}$ of each of the four deoxyribonucleoside triphosphates and $10 \mu \mathrm{l}$ of the sample solution containing the target DNA. Canine adenovirus type $1(\mathrm{CAdV}-1)$ strain was used as a positive control (Kiss et al., 1996). 
In the case of the hexon gene amplification, the mixtures were amplified with an initial denaturation at $94{ }^{\circ} \mathrm{C}$ for 10 min followed by 35 cycles at $94{ }^{\circ} \mathrm{C}$ for $30 \mathrm{sec}, 55^{\circ} \mathrm{C}$ for $30 \mathrm{sec}$, and $72{ }^{\circ} \mathrm{C}$ for $30 \mathrm{sec}$. There was a final extension at $72{ }^{\circ} \mathrm{C}$ for $7 \mathrm{~min}$. In the case of the polymerase gene, the initial denaturation was carried out also at $94{ }^{\circ} \mathrm{C}$ for $3 \mathrm{~min}$, but followed by 40 cycles at $94{ }^{\circ} \mathrm{C}$ for $1 \mathrm{~min}$, $46{ }^{\circ} \mathrm{C}$ for $1 \mathrm{~min}$, and $72{ }^{\circ} \mathrm{C}$ for $1 \mathrm{~min}$. The final extension step was at $72{ }^{\circ} \mathrm{C}$ for 7 min (Wellehan et al., 2004).

Ten $\mu$ of each sample were loaded on a $1 \%$ agarose gel containing $0.5 \mu \mathrm{g} / \mathrm{ml}$ ethidium bromide, and electrophoresed for one hour in a horizontal tank in TAE (Tris-Acetate-EDTA) buffer. As molecular mass marker, PstI-digested $\lambda$ phage DNA was loaded on the same gel. The gels were visualised on a UV transilluminator at $302 \mathrm{~nm}$ wavelength and photographed digitally. They were then excised from the gel and extracted using QIAquick Gel Extraction Kit (Qiagen).

\section{Sequence analysis and phylogeny}

Purified PCR products were sequenced directly on both strands using the Big-Dye terminator kit (ThermoFischer Scientific, Cat. No. 4337455) and a Perkin-Elmer (Branchburg, N.J., USA) thermal cycler, and analysed on ABI 377 automated DNA sequencers at the Biological Research Centre of the Hungarian Academy of Sciences (Szeged, Hungary). The sequences from this study were submitted to the GenBank and assigned to accession numbers MF509770 (polymerase) and MF509771 (hexon).

The nucleotide (nt) sequences were processed with ChromasPro (Technelysium Pty Ltd., Australia), and were verified by visual inspection, then compiled and compared using BLAST (NCBI) and Align plus 4 for Windows 95, version 4.0 (Scientific and Educational Software) programmes. Multiple alignments using aa sequences were performed using Align plus and MEGA 7.0 software packages. Distance matrix analysis was performed by the PHYLIP program package: ProtDist (JTT model), followed by Fitch (with global rearrangement). The final length of the edited multiple alignment was 138 aa in the case of the polymerase sequences; however, some of these were only 90 aa long (the missing residues were substituted with question marks as allowed in ProtDist). In the case of the hexon, sequences consisting of 82 amino acids were aligned. Phylogenetic trees were plotted by the MEGA 7.0 software.

The accession numbers of the AdV sequences used in the phylogenetic tree reconstruction are AC000009, AC000017, AC000191, AF172246, AF258784, AM749299, EU835513, FJ025912, GQ499375, HM368167, JF699046, JN377908, JX244189, JX244191, JX244192, JX885602, KJ563221, KM043089, KM043095, KP238322, KP295475, KP335092, T698852, KT698855, KU258176, KU258181, KX545420, KY753134, KY753142, LT841149, NC000942， NC014899, NC015932, NC020487, NC028107 and NC010956. 


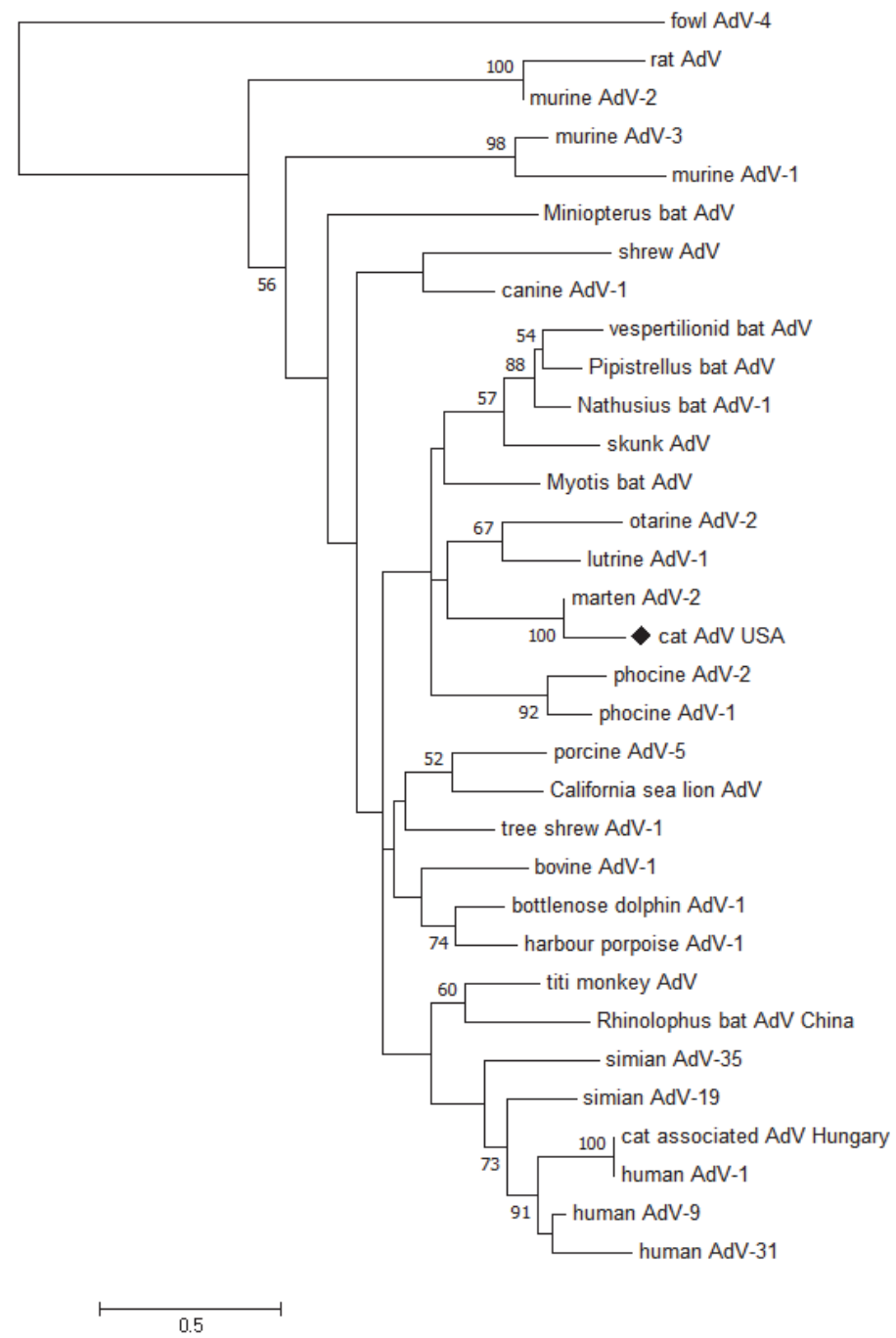

Fig. 1A. Phylogenetic tree constructed using the deduced amino acid sequences of the hexon gene fragment of different mastadenoviruses retrieved from the GenBank. Fowl adenovirus 4 sequence was used to root the tree. The word adenovirus was abbreviated in the name of the sequences ( $\mathrm{AdV}=$ adenovirus) for clarity. Bootstrap was not applied due to the shortness of the sequences. The bar indicates the number of substitutions per site

\section{Results}

Both PCRs yielded amplicons of the expected size. Direct sequencing revealed homogeneity of the products. After removal of the primer sequences, the size of the newly-determined sequences was 445 bp from the DNA polymerase 
and $253 \mathrm{bp}$ from the hexon genes, respectively. The base composition of both gene fragments was biased towards $\mathrm{A}+\mathrm{T}$, resulting in a mere $38 \%$ overall $\mathrm{G}+\mathrm{C}$ content.

With the semi-nested PCR method (Wellehan et al., 2004), a 148-aa fragment from the DNA polymerase of the cat virus was obtained. The corresponding sequences from other AdVs, found as the closest relatives to our virus in the GenBank, were retrieved and used in phylogeny inference. From some of these AdVs only a shorter fragment (encompassing 90 aa) was available, thus the calculation was adjusted to the full length (138-aa) alignment using question marks for the missing residues (Fig. 1A).

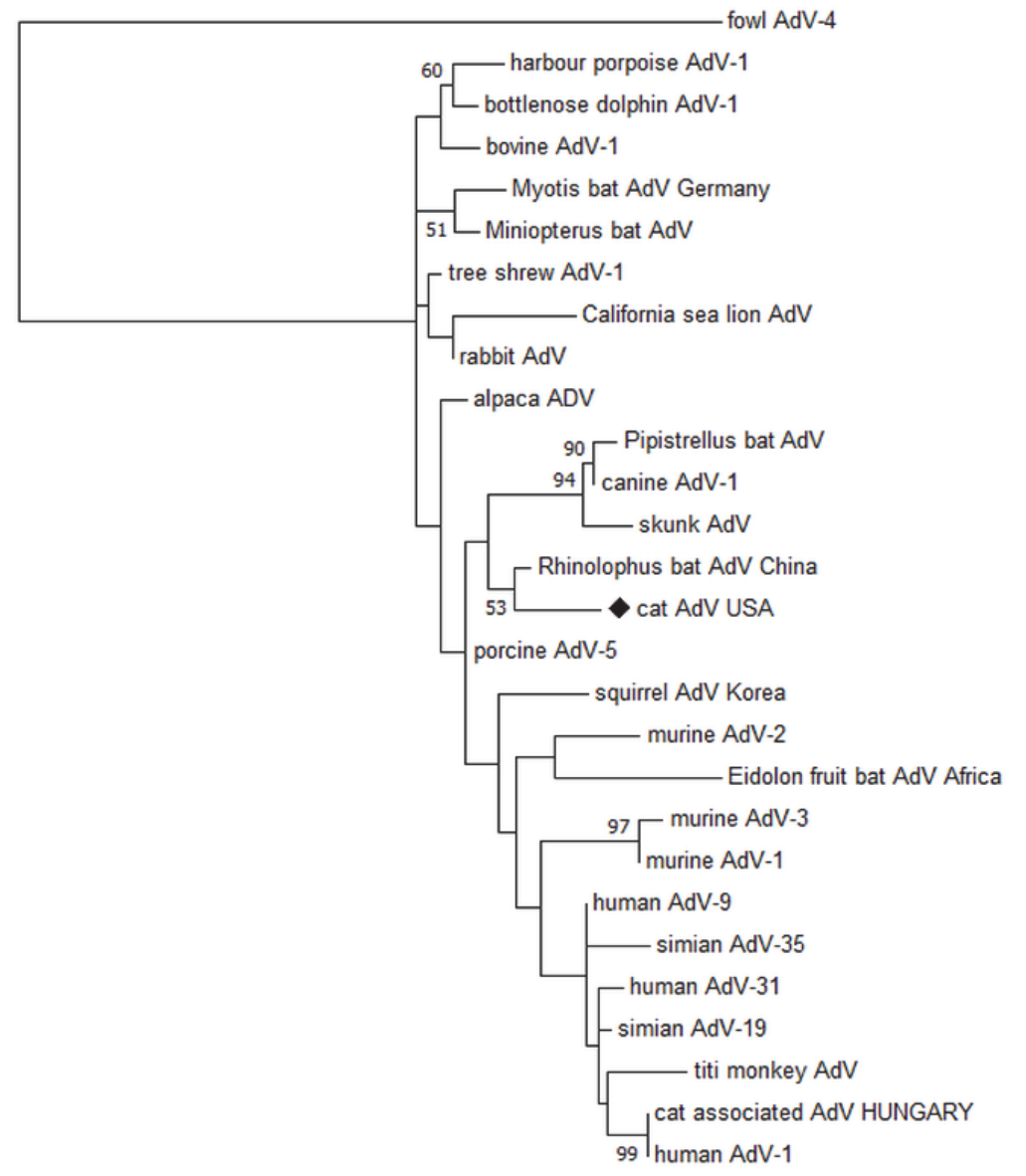

0.1

Fig. 1B. Phylogenetic tree constructed using the deduced amino acid sequences of the DNA polymerase gene fragment of different mastadenoviruses retrieved from the GenBank. Fowl adenovirus 4 sequence was used to root the tree. The word adenovirus was abbreviated in the name of the sequences ( $\mathrm{AdV}=$ adenovirus) for clarity. Bootstrap was not applied due to the very short length of the sequences. The bar indicates the number of substitutions per site 
The putative cat $\mathrm{AdV}$ appeared on a sister branch of that of the marten AdV (Walker et al., 2017) in a clade where additional AdVs originating from other carnivorous hosts, such as otters and sea lions, clustered as well. Interestingly, a number of bat AdVs were also placed here (Fig. 1A).

Unfortunately, many AdVs clustering in the vicinity of our cat virus are represented only by the PCR-amplified, short, DNA polymerase gene fragment in the public databases, and no other genomic sequences are available from them. Consequently, the topology of the other tree, based on hexon aa sequences, was slightly divergent (Fig. 1B). The putative cat AdV appeared as the closest relative to an AdV isolate obtained from horseshoe bat (Rhinolophus sinicus) in China most recently (Tan et al., 2017). The similarity of the hexon fragment to the corresponding part of this Rhinolophus bat AdV was $90 \%$.

Somewhat different results were obtained when the acquired partial gene sequences were compared at nt level. In the case of the hexon gene, the squirrel AdV (Kim et al., 2017), with $80 \%$ identity, seemed to be closest relative of our putative cat AdV. However, in the case of the DNA polymerase gene, the highest identity was merely $71 \%$ shared with the corresponding fragment of the AdV isolated from Miniopterus bat (Tan et al., 2017). As this discrepancy was largely due to the redundancy of the genetic code, only the aa-sequence-based trees are shown.

The host origin of AdVs that appeared as the closest relatives of the putative novel cat AdV on the two trees was also rather divergent (Fig. 1) essentially because not every AdV is represented by both (hexon and DNA polymerase) gene fragments in the GenBank.

\section{Discussion}

The detection of nucleic acid from FFPE specimens is challenging, due to the extensive cross-linking of all tissue components during the fixation process. These changes include chemical modification of the DNA, cross-linking of DNA with other molecules, degradation of the DNA, and the limited amount of nucleic acid in the samples. Successful PCR amplification is more probable when short fragments of nucleic acids are targeted (Little et al., 2006; Jacobs et al., 2007; Oosting et al., 2007; Killian et al., 2009). In our study, PCR amplification of fragments of the hexon and DNA polymerase genes from FFPE samples of the cat yielded amplicons of the expected size. Since our main aim was to gain sequence data from the suspected AdV involved in the generalised infection, we used pooled samples and not individual organ material (Kennedy and Mullaney, 1993).

The phylogenetic calculations, performed by using nt or deduced aa sequences of the two gene fragments, implied different AdVs as the most closely related relatives of the putative cat AdV. This fact, together with the calculated identity and similarity percentage values, suggests that the newly detected virus 
represents a novel AdV species within the genus Mastadenovirus. The demarcation criteria of $\mathrm{AdV}$ species include at least $10 \%$ divergence in the nt sequence of the DNA-dependent DNA polymerase gene. The partial polymerase sequence, obtained from the feline FFPE sample in the present study, fulfils this criterion (Harrach, 2008). Other characteristics (such as genome organisation, haemagglutination properties or cross-neutralisation values) used in AdV species demarcation (Harrach et al., 2011) could not be investigated since the virus was neither isolated nor fully sequenced.

The AdV sequences that shared highest similarity at the aa level with the putative cat AdV were from different host species, marten and bats, that are evolutionarily distant from each other as well as from members of the family Felidae. This supports our speculation that this novel putative AdV represents an independent evolutionary lineage. Still, the host specificity of this virus remains to be confirmed by further demonstration of the same (or closely related) virus(es) in samples of other felid hosts.

In general, the host range of AdVs, including mastadenoviruses, is narrow, limited to a single or several closely related species so that co-evolution of AdVs with their vertebrate hosts has been hypothesised (Harrach, 2000). Nonetheless, clear signs of host switches of smaller, or sometimes larger, scale have also been recognised (Benkö and Harrach, 2003). As a result of host switching events, a certain host species may harbour several AdVs that are very divergent, representing sometimes distant virus lineages (Vidovszky et al., 2015; Ballmann and Harrach, 2016).

The significantly higher seroprevalence of antibodies to AdV in cats that are also infected with FIV, and the fact that the cat in the present communication was infected with FeLV, underscore the relationship between AdV-associated disease and immunodeficiency. The same connection is known in humans. Individuals with normally harmless, persistent $\mathrm{AdV}$ infection might develop generalised, sometimes even fatal, disseminated adenoviral disease in case of severe immunosuppression, caused by HIV infection or by pretreatment for organ transplantation (Echavarría, 2008). It is most probable that cats can also be naturally infected by AdVs without clinical signs. Superinfection by FIV or FeLV, or other feline pathogens causing immunosuppression, can lead to severe disease manifestation. Alternatively, cats with seriously weakened immune functions may easily acquire secondary bacterial or viral infections. In such cases, the possibility of infection by adenoviruses of different host origin cannot be excluded. Indeed, HAdV-1 was first detected in an FIV-infected cat in a previous survey (Lakatos et al., 1999a).

The presence of low-level antibodies to human AdVs in cats has been described in connection with vaccination trials using recombinant HAdV-5 as gene-delivery vector (Gonin, 1995). Our results indicate that, apart from HAdVs from the species Human mastadenovirus C (Lakatos et al., 1999b; Phan et al., 
2006; Luiz et al., 2010), perhaps a distinct putative feline AdV also infects cats. Although the overall amount of the studied genomic sequences of the putative cat AdV is scarce, their base composition biased towards high $\mathrm{A}+\mathrm{T}$ content allows for hypothesising a host switch event, as the existence of such a connection has been proposed before (Benkö and Harrach, 2003; Wellehan et al., 2004).

Further studies, including the acquisition of additional genomic fragments, as well as data regarding its prevalence, will be needed to confirm that the newly-detected virus is primarily associated with cats. Presently, as no other host can be assigned to it, this virus can be considered as a novel distinct feline adenovirus.

\section{Acknowledgements}

The study was sponsored by the TÁMOP-4.2.2.B-10/1 and TÁMOP-4.2.1.B11/2/KMR-2011-0003 projects.

\section{References}

Allard, A., Girones, R., Juto, P. and Wadell, G. (1990): Polymerase chain reaction for detection of adenoviruses in stool samples. J. Clin. Microbiol. 28, 2659-2667.

Ballmann, M. Z. and Harrach, B. (2016): Detection and partial genetic characterisation of novel avi- and siadenoviruses in racing and fancy pigeons (Columba livia domestica) Acta Vet. Hung. 64, 514-528.

Benkö, M. and Harrach, B. (2003): Molecular evolution of adenoviruses. Curr. Top. Microbiol. Immunol. 272, 3-35.

Chakrabarti, S., Milligan, D. W., Moss, P. A. and Mautner, V. (2004): Adenovirus infections in stem cell transplant recipients: recent developments in understanding of pathogenesis, diagnosis, and management. Leuk. Lymphoma 45, 873-885.

Chandler, F. W. and Gorelkin, L. (1983): Immunofluorescence staining of adenovirus in fixed tissues pretreated with trypsin. J. Clin. Microbiol. 17, 371-373.

Chouinard, L., Martineau, D., Forget, C. and Girard, C. (1998): Use of polymerase chain reaction and immunohistochemistry for detection of canine adenovirus type 1 in formalin-fixed, paraffin-embedded liver of dogs with chronic hepatitis or cirrhosis. J. Vet. Diagn. Invest. 10, 320-325.

Echavarría, M. (2008): Adenoviruses in immunocompromised hosts. Clin. Microbiol. Rev. 21, $704-715$.

Echavarría, M., Forman, M., van Tol, M. J. D., Vossen, J. M., Charache, P. and Kroes, A. C. M. (2001): Prediction of severe disseminated adenovirus infection by serum PCR. Lancet 358, 384-385.

Garcia-Morante, B., Pénzes, J. J., Costa, T., Martorell, J. and Martínez, J. (2016): Hyperplastic stomatitis and esophagitis in a tortoise (Testudo graeca) associated with an adenovirus infection. J. Vet. Diagn. Invest. 28, 579-583.

Gonin, P., Fournier, A., Oualikene, W., Moraillon, A. and Eloit, M. (1995): Immunization trial of cats with a replication-defective adenovirus type 5 expressing the ENV gene of FIV. Vet. Microbiol. 45, 393-401.

Gupta, P. P. (1978): Inclusion body hepatitis in a black panther (Panthera pardus pardus). Zbl. Vet. Med. B 25, 858-860.

Harrach, B. (2000): Reptile adenovirus in cattle? Acta Vet. Hung. 48, 485-490. 
Harrach, B. (2008): Adenoviruses: general features. In: Mahy, B. W. and van Regenmortel, M. H. (eds) Encyclopedia of Virology. Elsevier, Oxford. pp. 1-9.

Harrach, B., Benkő, M., Both, G. W., Brown, M., Davison, A. J., Echavarría, M., Hess, M., Jones, M. S., Kajon, A., Lehmkuhl, H. D., Mautner, V., Mittal, S. K. and Wadell, G. (2011): Family Adenoviridae. In: King, A. M. Q., Lefkowitz, E., Adams, M. J. and Carstens, E. B. (eds) Virus Taxonomy: IXth Report of the International Committee on Taxonomy of Viruses. Elsevier, San Diego. pp. 125-141.

Horváth, M., Szücs, Gy. and Új, M. (1996): Enteral adenovirus and invagination in infancy [in Hungarian]. Orvosi Hetilap 137, 1933-1934.

Huang, W., Sheehy, T. M., Moore, L. E., Hsing, A. W. and Purdue, M. P. (2010): Simultaneous recovery of DNA and RNA from formalin-fixed paraffin-embedded tissue and application in epidemiologic studies. Cancer Epidemiol. Biomarkers Prev. 19, 973-977.

Jacobs, S., Thompson, E. R., Nannya, Y., Yamamoto, G., Pillai, R., Ogawa, S., Bailey, D. K. and Campbell, I. G. (2007): Genome-wide, high-resolution detection of copy number, loss of heterozygosity, and genotypes from formalin-fixed, paraffin-embedded tumor tissue using microarrays. Cancer Res. 69, 2544-2551.

Kaján, G. L., Sameti, S. and Benkö, M. (2011): Partial sequence of the DNA-dependent DNA polymerase gene of fowl adenoviruses: a reference panel for a general diagnostic PCR in poultry. Acta Vet. Hung. 59, 279-285.

Kennedy, F. A. and Mullaney, T. P. (1993): Disseminated adenovirus infection in a cat. J. Vet. Diagn. Invest. 5, 273-276.

Killian, J. K., Bilke, S., Davis, S., Walker, R. L., Killian, M. S., Jaeger, E. B., Chen, Y., Hipp, J., Pittaluga, S., Raffeld, M., Cornelison, R., Smith, W. I., Bibikova, M., Fan, J. B., EmmertBuck, M. R., Jaffe, E. S. and Meltzer, P. S. (2009): Large-scale profiling of archival lymph nodes reveals pervasive remodeling of the follicular lymphoma methylome. Cancer Res. 69, 758-764.

Kim, J. I., Oh, S. J., Lee, I., Park, S., Park, M. S. and Song, K. J. (2017): Evolutionary relationships of the hexon and penton base genes of novel squirrel adenovirus. Mol. Phylogenet. Evol. 116, 25-29.

Kiss, I., Matiz, K., Allard, A., Wadell, G. and Benkő, M. (1996): Detection of homologous DNA sequences in animal adenoviruses by polymerase chain reaction. Acta Vet. Hung. 44, 243251.

Lakatos, B., Farkas, J., Ádám, É., Dobay, O., Jeney, C., Nász, I. and Ongrádi, J. (2000): Serological evidence of adenovirus infection in cats. Arch. Virol. 145, 1029-1033.

Lakatos, B., Farkas, J., Ádám, É., Jarrett, O., Egberink, H. F., Bendinelli, M., Nász, I. and Ongrádi, J. (1996): Data to the adenovirus infection in cats in Europe [in Hungarian, with English abstract]. Magy. Allatorvosok Lapja 51, 543-545.

Lakatos, B., Farkas, J., Egberink, H. F., Vennema, H., Horzinek, M. C. and Benkő, M. (1999a): Detection of adenovirus hexon sequence in a cat by polymerase chain reaction (Short communication). Acta Vet. Hung. 47, 493-497.

Lakatos, B., Knotek, Z., Farkas, J., Ádám, É., Dobay, O. and Nász, I. (1999b): Adenovirus infection in cats. An epidemiological survey in the Czech Republic. Acta Vet. Brno 68, 275-280.

Lauer, K. P., Llorente, I., Blair, E., Seto, J., Krasnov, V., Purkayastha, A., Ditty, S. E., Hadfield, T. L., Buck, C., Tibbetts, C. and Seto, D. (2004): Natural variation among human adenoviruses: genome sequence and annotation of human adenovirus serotype 1. J. Gen. Virol. 85, 2615-2625.

Little, S. E., Vuononvirta, R., Reis-Filho, J. S., Natrajan, R., Iravani, M., Fenwick, K., Mackay, A., Ashworth, A., Pritchard-Jones, K. and Jones, C. (2006): Array CGH using whole genome amplification of fresh-frozen and formalin-fixed, paraffin-embedded tumor DNA. Genomics 87, 298-306.

Luiz, L. N., Leite, J. P., Yokosawa, J., Carneiro, B. M., Pereira Filho, E., Oliveira, T. F., Freitas, G. R., Costa, L. F., Paula, N. T., Silveira, H. L., Nepomuceno, J. C. and Queiróz, D. A. 
(2010): Molecular characterization of adenoviruses from children presenting with acute respiratory disease in Uberlândia, Minas Gerais, Brazil, and detection of an isolate genetically related to feline adenovirus. Mem. Inst. Oswaldo Cruz 105, 712-716.

Oosting, J., Lips, E. H., van Eijk, R., Eilers, P. H. C., Szuhai, K., Wijmenga, C., Morreau, H. and van Wezel, T. (2007): High-resolution copy number analysis of paraffin-embedded archival tissue using SNP BeadArrays. Genome Res. 17, 368-376.

Phan, T. G., Shimizu, H., Nishimura, S., Okitsu, S., Maneekam, N. and Ushijima, H. (2006): Human adenovirus type 1 related to feline adenovirus: evidence of interspecies transmission. Clin. Lab. 52, 515-518.

Pring-Åkerblom, P. and Adrian, T. (1994): Type- and group-specific polymerase chain reaction for adenovirus detection. Res. Virol. 145, 25-35.

Scott, T. T. and Hammond, G. W. (1992): Conserved sequences of the adenovirus genome for detection of all human adenovirus types by hybridisation. J. Clin. Microbiol. 30, 1703-1710.

Smyth, J. A., Benkő, M., Moffett, D. A. and Harrach, B. (1996): Bovine adenovirus type 10 identified in fatal cases of adenovirus-associated enteric disease in cattle by in situ hybridization. J. Clin. Microbiol. 34, 1270-1274.

Smyth, J. A., Moffett, D. A., van Garderen, E. and Orr, J. P. (1999): Examination of adenovirustypes in intestinal vascular endothelial inclusions in fatal cases of enteric disease in cattle, by in situ hybridisation. Vet. Microbiol. 70, 1-6.

Tan, B., Yang, X. L., Ge, X. Y., Peng, C., Liu, H. Z., Zhang, Y. Z., Zhang, L. B. and Shi, Z. L. (2017): Novel bat adenoviruses with low $\mathrm{G}+\mathrm{C}$ content shed new light on the evolution of adenoviruses. J. Gen. Virol. 98, 739-748.

Vidovszky, M., Kohl, C., Boldogh, S., Görföl, T., Wibbelt, G., Kurth, A. and Harrach, B. (2015): Random sampling of the Central European bat fauna reveals the existence of numerous hitherto unknown adenoviruses. Acta Vet. Hung. 63, 508-525.

Wadell, G. (1984): Molecular epidemiology of human adenoviruses. Curr. Topics Microbiol. Immunol. 110, 191-200.

Walker, D., Gregory, W. F., Turnbull, D., Rocchi, M., Meredith, A. L., Philbey, A. W. and Sharp, C. P (2017): Novel adenoviruses detected in British mustelids, including a unique Aviadenovirus in the tissues of pine martens (Martes martes). J. Med. Microbiol. 66, 1177-1182.

Wellehan, J. F. X., Johnson, A. J., Harrach, B., Benkő, M., Pessier, A. P., Johnson, C. M., Garner, M. M., Childress, A. and Jacobson, E. R. (2004): Detection and analysis of six lizard adenoviruses by consensus primer PCR provides further evidence of a reptilian origin for the atadenoviruses. J. Virol. 78, 13366-13369. 